\title{
ESTUDIO DE LA VULNERABILIDAD DE LAS REDES DE TRANSPORTE DESDE UNA PERSPECTIVA GEOGRÁFICA ${ }^{1}$.
}

\section{VULNERABILITY STUDY OF TRANSPORT NETWORK GEOGRAPHICAL PERSPECTIVE.}

\author{
Eduardo Rodríguez Núñez \\ Universidad Complutense de Madrid \\ eduardor@ghis.ucm.es \\ Recibido: marzo, 2012. \\ Versión final aceptada: enero, 2013.
}

PALABRAS CLAVE: accesibilidad, vulnerabilidad, SIG, redes de carreteras, redes de metro.

KEYWORDS: accessibility, vulnerability, GIS, road networks, metro networks.

\section{RESUMEN}

En la planificación y gestión de las redes de transporte no suele hacerse referencia a la vulnerabilidad de las mismas. Las consecuencias económicas, sociales y territoriales de los daños producidos sobre estas redes por acontecimientos de carácter natural o humano, ya sean espontáneos o deliberados, se extienden por el o los territorios afectados con distinto grado de incidencia. Desde una visión geográfica se presentan los casos estudiados, con un Sistema de Información Geográfica, relativos a la valoración de la vulnerabilidad de dos redes de transporte, la de carreteras de la isla de Mallorca y la de Metro de Madrid, mediante el análisis de la variación de la accesibilidad de los puntos de origen y destino de dichas redes y su impacto en el territorio que comprenden.

\section{ABSTRACT}

In the planning and management of transport networks often referred to the vulnerability of the same. The economic, social and territorial damage on these occurrences networks by natural or human, whether spontaneous or deliberate spread over the territory or territories affected with varying degrees of incidence. From a geographic view the case studies are presented with a Geographic Information System relating to the assessment of the vulnerability of two networks of transport, the road of the island of Mallorca and Madrid Metro, by analyzing the variation in the accessibility of the points of origin and destination of such networks and their impact on the territory comprising.

\footnotetext{
1 El presente artículo procede de la comunicación científica presentada en las Jornadas de Estudios Regionales: Redes y sus territorios: Incidencia en el desarrollo regional. AGE. Sevilla, Junio de 2012.
}

ISSN: 0212-8594 ISSN-e: 2340-2776 № DOI: http://dx.doi.org/10.12795/rea.2012.i29.03 


\section{INTRODUCCIÓN.}

En la actualidad, los sistemas sociales y/o económicos, sobre todos los más avanzados, presentan unos niveles de complejidad que, en diversas situaciones, los deja expuestos fácilmente a numerosos riesgos y contingencias que inicialmente no tenían previsto afrontar, lo que no en pocas situaciones se traduce en consecuencias lamentables, incluso con pérdidas de vidas humanas. Las raíces de estos riesgos y peligros son muy heterogéneas, distinguiendo dos categorías, los de carácter natural, como las inundaciones, terremotos, erupciones volcánicas, tempestades, huracanes, nevadas intensas, etc., y los derivados por actos humanos, que deben diferenciarse entre los involuntarios, como los accidentes de tráfico, y los deliberados (revueltas sociales y revoluciones, atentados terroristas, etc.), los cuales a veces no causan menos perjuicios que los originados por elementos de la naturaleza.

La inmensa mayoría de sucesos con efectos importantes tienen en un reflejo a nivel espacial y también debe ser tenido en cuenta el intervalo temporal en el que se dan. Es imprescindible valorar los perjuicios de tipo económico, social y, sobre todo, personal, derivados de las secuelas directas de la vulnerabilidad sobre los bienes materiales, en los que se incluyen las infraestructuras de diferente índole.

Una alteración en las redes de transporte, por pequeña que sea, puede llevar a que los territorios por donde discurren sufran determinados daños que reduzcan, o incluso imposibiliten, un adecuado movimiento e intercambio de bienes y personas, tal y como se desarrolla en una situación de normalidad de la red. Así, la trascendencia de las interrupciones en los distintos tipos de redes varía en primer lugar en su extensión, dependiendo de si las mismas afectan parcial o totalmente a la red, y de otro factor no menos importante, como es el intervalo de tiempo que abarcan, el cual indicará cuándo se puede volver a usar la red con normalidad.

Un ejemplo claro y evidente es el aumento del automóvil como medio de transporte privado, que ejerce tal demanda sobre una red de infraestructuras como son las carreteras que cualquier evento que derive en problemas en las mismas suele dar lugar a determinados perjuicios con sus considerables consecuencias, y según el nivel o la gravedad de estos efectos demostrará el nivel de vulnerabilidad de dichas infraestructuras. En el caso de una red de transporte público masiva como es una red de metro, una interrupción determinada promoverá una atención específica sobre la misma, tanto por los efectos económicos como en términos de tiempo emplea dotanto para los usuarios en particular como para el conjunto del ámbito metropolitano que abarca, en general. En cualquier caso, sea el tipo de red que sea, la valoración de los desplazamientos lleva a que la preocupación surja cuando una alteración de la red modifica y prolonga el recorrido más tiempo del inicialmente previsto, más que en términos económicos, si bien ambos aspectos están estrechamente imbricados. 
La estimación de la vulnerabilidad de una red presenta en primer lugar la dificultad de proceder a computarla con la mayor fiabilidad, partiendo de diversos factores de su entorno territorial, como los económicos, políticos, jurídicos, sociales y ambientales (Ribas, A. y Saurí, D., 2006). Así, el término vulnerabilidad plantea de partida un significado complejo y multifacético, dependiendo de los elementos implicados en cada una de las situaciones en las que se manifieste.

Un estudio de vulnerabilidad de las redes de transporte habrá de mostrar la fiabilidad y resistencia de las mismas, su funcionamiento anterior, en el momento de producirse un incidente y posterior, el grado de seguridad que aportan y, sobre todo, las secuelas para la población y la actividad económica del lugar afectado (Díaz Pineda, J., 2000).Se examinará la relevancia de todos sus tramos, nodos y conexiones, de los riesgos a los que se halla expuesta, de sus elementos más débiles y los posibles itinerarios alternativos a emplear en caso de una alteración parcial de la misma para que sus efectos sean los mínimos posibles y se pueda seguir utilizando -entrando en juego el término resiliencia (Chen, A. et al., 2007).

Desde un punto de vista geográfico se pretende iniciar análisis de la vulnerabilidad de distintas redes de transporte mediante Sistemas de Información Geográfica para comprobar los efectos sobre determinados territorios, tras la aparición de un evento que cause efectos perniciosos en dicha red, y obtener resultados que muestren sus debilidades así como considerar soluciones que aminoren su vulnerabilidad.

\section{ANTECEDENTES.}

Los estudios sobre la vulnerabilidad de redes de transporte son relativamente recientes. En estos últimos años se han establecido los principales fundamentos teóricos de la vulnerabilidad, distintas definiciones de la misma, múltiples escenarios de riesgo posibles y ciertos indicadores concretos relacionados con la movilidad, como la población implicada en los movimientos cotidianos, sobre todo en áreas urbanas (Rey, F. y Cardozo, O., 2008), junto a su conocimiento sobre los peligros y amenazas sobre la red (Díaz Pineda, J., 2000), así como su surgimiento en cualquier ámbito geográfico según sus características (Ribas, A. y Saurí, D., 2006).Su tratamiento desde el campo de la Geografía no ha sido especialmente sistemático, a pesar de su estrecha relación con el análisis espacial.

En una red de transporte, la vulnerabilidad se establece a partir de los hechos que reducen el nivel o calidad de servicio de dicha red (Johnson, R., 1987). En ciertos casos se considera ligada al concepto de accesibilidad (Chen, A. et al., 2007), al reducirse esta última en el ámbito afectado. De hecho, esta estrecha relación hace que se llegue a denominar a la vulnerabilidad como "accesibilidad reducida", problema de insuficiente nivel de servicio o la susceptibilidad a incidentes que reducen notablemente el rendimiento de la red (Berdica, K., 2002), capacidad de seguir trabajando correctamente tras una alteración de la misma (Johnson, R., 1987) o el grado de

ISSN: 0212-8594 ISSN-e: 2340-2776 № DOI: http://dx.doi.org/10.12795/rea.2012.i29.03

REA 29 (2012): 59-82

http://www.publius.us.es/estudios_andaluces 
validez de una red para seguir funcionando tras sufrir una alteración (Aymerich, O. y Robusté, F., 1990) o como la importancia de un elemento de la red cuyo fallo disminuya su eficiencia.

La importancia de la accesibilidad en el tema de la vulnerabilidad de redes parte de que la primera conformaría los usos del suelo (Hansen, W., 1959), aunque actualmente distintos estudios mostrarían que la distribución de éstos en las ciudades es la que acaba determinando la accesibilidad de los residentes a las actividades, como la interacción entre lugares de residencia y de trabajo, de modo que en un ámbito geográfico dado la accesibilidad sería la cantidad de oportunidades que los individuos pueden alcanzar, según sus actividades diarias y sus localizaciones fijas (hogar, trabajo, etc.), confrontando la accesibilidad individual (un buen indicador de la calidad de vida) con la accesibilidad de lugar (facilidad con la que la población llega a las localizaciones) (Kwan, M.P. et al., 2003). Las áreas metropolitanas son enclaves de elevada accesibilidad conectadas mediante redes de transporte que favorecen el proceso continuo de expansión geográfica de las actividades, mostrando la correlación entre las características demográficas (la población, su densidad) del espacio analizado y los diferentes grados de accesibilidad en las distintas áreas cubiertas por dichas redes, representados en las paradas o estaciones de metro caracterizadas por los nodos. Por ejemplo, una mayor accesibilidad en las zonas centrales de la ciudad elevaría los activos de valor de mercado y una expansión de la red en zonas que ya disponen de metro aumenta la accesibilidad en estas áreas, lo que provoca que el precio del suelo y de las viviendas se incremente (Dragu, V. et al., 2011). La mayoría de los servicios y empleos se sitúan cerca de las estaciones, de modo que cada estación, sobre todo en áreas céntricas, suele mostrar una cantidad elevada de pasajeros (Jung, W. et al., 2008).

La accesibilidad para ir desde una localización concreta a distintas ubicaciones en donde se producen diferentes actividades se basa en tres criterios esenciales: Los núcleos de demanda o lugares en los que reside la población, los puntos de oferta o áreas donde se encuentra el empleo, el bien o el servicio requerido y la distancia que separa a ambos, considerada esta última más en valores de tiempo de viaje que en unidades de distancia (Dragu, V. et al., 2011; Litman, T., 2011; Jung, V. et al, 2008).

El uso de valores de accesibilidad para estimar la vulnerabilidad de una red surge a partir de los daños y costes socioeconómicos que las interrupciones de la red suponen para la sociedad, medidos en términos de aumento del tiempo de viaje (Chen, A. et al., 2007).Los análisis llevados a cabo mediante la variación de la accesibilidad de los lugares de destino, midiéndola antes y después de una alteración hipotética en uno o más tramos de la red (Chang, S., 2003, Sohn, J., 2006) y según su peso o importancia, podrían mostrar los cambios que se harían en los flujos origen-destino, en la generación de viajes, en su distribución temporal, en su distribución espacial, en la elección de modos de viaje y en la elección de rutasy en otras cuestiones relativas a la movilidad que influyen directamente en el bienestar de la población, y de esta manera

ISSN: 0212-8594 ISSN-e: 2340-2776 № DOI: http://dx.doi.org/10.12795/rea.2012.i29.03

REA 29 (2012): 59-82

http://www.publius.us.es/estudios_andaluces 
obtener la accesibilidad diferencial, en términos de incremento del tiempo de desplazamiento.

La vulnerabilidad sería el parámetro que midiese la respuesta de las redes complejas afectadas por ataques en sus nodos y arcos y que permitiría encontrar el componente crítico de las mismas a fin de mejorar su seguridad. Un tramo será o no importante para el correcto funcionamiento de la red si, al eliminarlo o dejar de ser operativo, tiene un efecto notable sobre el rendimiento global del sistema - debiéndole dar prioridad en las tareas de rehabilitación (Sohn, J., 2006)- y deriva en unas determinadas consecuencias para los usuarios de la red (Jenelius, E., 2009a), como un incremento total en el tiempo de viaje, por ejemplo, lo cual implica una identificación de los tramos más importantes de la red (Latora, V. et al., 2005) o, por lo menos, de los que pueden producir un mayor impacto sobre los viajeros y de esta manera, saber el grado de vulnerabilidad que puede tener la red, con el fin de reducir los riesgos o consecuencias de posibles ataques. El peso de un tramo que conecta dos estaciones viene representado por el flujo de pasajeros en ambos sentidos entre ellas y la importancia de una estación se corresponde con el número de pasajeros que entran y salen de esa estación (Jung, W. et al., 2008).Como ejemplo, averiguar qué estaciones y rutas pueden ser más importantes en una red de metro, pues un mal funcionamiento de las mismas colapsará toda o buena parte de la red (Criado, R. et al., 2008).

La vulnerabilidad de redes de transporte se ha centrado principalmente en las situaciones de mal funcionamiento de las redes de carreteras (Berdica, K., 2007; Erath, A. et al., 2008; Jenelius, E., 2006a, 2006b, 2007, 2009a, 2009b; Taylor, A. et al., 2006) por su cuantioso impacto tanto a nivel cuantitativo (número de viajeros afectados, costes económicos asociados, etc.) como cualitativo (implicaciones a nivel territorial, rendimiento de las comunicaciones de un determinado territorio, etc.). El rendimiento de las carreteras se relaciona con la fiabilidad, entendida ésta como unas condiciones adecuadas de serviciabilidad (o nivel de servicio) o un correcto funcionamiento en las redes en un determinado momento, la cual se puede ver alterada en una situación de vulnerabilidad durante un periodo de tiempo dado. Esto se puede trasladar a otros sistemas de transporte importantes (Berdica, K., 2002), como las redes de metro, cuyo funcionamiento es esencial para numerosas grandes ciudades en todo el mundo y sus áreas metropolitanas. Una red de carreteras fiable mantendría un tráfico constante y con seguridad, con rutas alternativas que absorbiesen la demanda (o al menos, parte de ella) en circunstancias en que algún tramo de la red se hallase cortado, por tanto es poco vulnerable (Berdica, K., 2002).

Tanto las redes de carreteras como las de metro y otras redes de transportes se incluirían en lo que se denominan Sistemas de Transporte Degradables (Degradable Transport Systems o DTS), los cuales sugieren que estos sistemas se degradan como resultado de una amplia variedad de acontecimientos diversos (terremotos, inundaciones, meteorología adversa, accidentes de tráfico, mantenimiento inadecuado, etc.) (Nicholson, A. y Du, Z., 1997). La duración de la degradación tiene su

ISSN: 0212-8594 ISSN-e: 2340-2776 № DOI: http://dx.doi.org/10.12795/rea.2012.i29.03

REA 29 (2012): 59-82

http://www.publius.us.es/estudios_andaluces 
relevancia, ya que su impacto socioeconómico aumenta claramente al incrementarse el tiempo necesario para la reparación/sustitución del tramo o tramos afectados. La extensión del daño al sistema de transporte y la velocidad de su restablecimiento de este último son por tanto factores de suma importancia.

Determinados estudios de la vulnerabilidad (así como de su término contrario, la robustez) de las redes de metro, consideran a la misma como un grafo con sus vértices y sus arcos (Criado, R. et al., 2004, 2006, 2008; Dragu, V. et al., 2011; Han, S. et al., 2009; Kwan, K. et al., 2003; Latora, V. et al., 2002, 2005), lo cual permitiría verificar el número de componentes que se mantienen conectados a la red o el número de trayectos disponibles que conectan cada par de vértices restantes después de una eliminación de nodos o tramos (Criado, R. et al., 2004), a través de una función de Vulnerabilidad (V), definida sólo por grafos conectados, y reconocer así sus elementos críticos para mejorar su seguridad. Este concepto está relacionado con el descenso del rendimiento de la red a causa de la eliminación de vértices y arcos o de la eficiencia de la red cuando alguno de sus elementos (nodos o arcos) se colapsa (Criado, R. et al., 2006). Las estrategias de planificación de las redes de metro deberían tener en cuenta esta vulnerabilidad para mejorar su diseño y funcionamiento (Han, S. et al., 2009).

Un incremento de la densidad de la red puede paliar su vulnerabilidad, ya que si ésta es más densa, menores son los efectos de la interrupción de uno o varios tramos, dándola un elevado grado de fiabilidad (Dragu, V. et al., 2011), pues facilitará los desplazamientos y aportará rutas alternativas, lo que la hace menos vulnerable, mientras que una red poco densa agrava los problemas en caso de alteraciones (Cova, T.,1999). Una de las soluciones contempladas es la redundancia del sistema, esto es, establecer una conexión alternativa de algún tramo o conjunto de los mismos afectados por una alteración, si representan una mayor fiabilidad o un beneficio importante para el resto de la red, al cubrir una proporción de la demanda. En las redes de metro los posibles recorridos alternativos o redundantes que posibiliten a los usuarios evitar los tramos cortados son mucho más escasos que en las carreteras, o incluso inexistentes, con lo cual los efectos en los tiempos de desplazamiento son especialmente notables, al incrementarse considerablemente.

Los Sistemas de Información Geográfica (SIG) se pueden usar para caracterizar los riesgos de un área que pueden afectar a las carreteras y comprobar la capacidad de los tramos de la red de soportarlos y mantener su funcionamiento tras producirse un evento que la altere, creando un modelo con el que realizar la posterior evaluación de la vulnerabilidad de la red viaria (Díaz Pineda, J., 2000)

Los análisis de la vulnerabilidad de redes de transporte son cruciales para estas infraestructuras. Se debe tener en cuenta la gestión de los riesgos a los que se exponen en su planificación, construcción y mantenimiento, identificar sus elementos críticos, las alternativas de uso que ofrecen, las posibles consecuencias y su manejo, los costes económicos y sociales preventivos y paliativos generados por los eventos

ISSN: 0212-8594 ISSN-e: 2340-2776 № DOI: http://dx.doi.org/10.12795/rea.2012.i29.03

REA 29 (2012): 59-82

http://www.publius.us.es/estudios_andaluces 
que las pudieran alterar. En definitiva, hacerlas más fiables y robustas y menos vulnerables a las interrupciones.

La propuesta es establecer un marco general que defina los daños críticos, la vulnerabilidad estructural y las mejoras esenciales de la red. Para obtener estos elementos se mediría el perjuicio del sistema en general con unas referencias observables como la caída relativa del rendimiento o las variaciones del funcionamiento de la red (Latora, V. et al., 2005).

\section{ESTUDIOS DE CASO. ANÁLISIS DE VULNERABILIDAD DE DOS REDES DE TRANSPORTE.}

La metodología seguida para la evaluación de la vulnerabilidad de las redes de transporte consideradas parte del empleo de otro factor inicial, la accesibilidad, la cual muestra la disposición, mayor, menor o incluso nula, de comunicarse entre determinados puntos o áreas de un territorio, a partir de la variación de la misma entre una situación de normalidad y otra de alteración de toda o de parte de la red. Toda la cartografía obtenida así como los cálculos realizados se han llevado a cabo con el software ArcGIS, tanto con las versiones 9.3 como 10.

\subsection{ANÁLISIS DE LA RED DE CARRETERAS DE UN TERRITORIO INSULAR - ISLA DE MALLORCA.}

La red de carreteras de Mallorca analizada (Figura 1) dispone de 401 tramos y en el estudio se han considerado 57 áreas territoriales, que son los 5 distritos de Palma (dividido así el término municipal por su importancia en cuanto a población) más los otros 52 municipios, dispuestos en forma de centroides.

En cuanto a los datos utilizados, se dispone de su población a 1 de Enero de 2009, de la longitud de los tramos y del tiempo de viaje en cada uno de ellos a partir de su velocidad máxima legal, así como del tiempo de viaje interno de cada municipio, que va en función de unos rangos de población considerados. Todos los núcleos de población de los municipios serán tanto orígenes como destinos, con el fin de poder elaborar una matriz orígenes-destino inicial con la que comenzar el estudio, en la que se emplea el tiempo de viaje entre ellos, no la distancia que los separa. Incluso se consideran los tiempos de desplazamiento dentro de su ámbito para mostrar los viajes internos, estableciendo un rango según la población de cada término (Tabla 1).

Con el propósito de estimar la vulnerabilidad de esta red, se compararán los valores de accesibilidad potencial que cada término presenta en una situación de funcionamiento correcto de toda la red y los que muestran a partir de distintas interrupciones en determinados tramos de la misma, representados con siete escenarios de interrupciones ficticias y otro relativo a una situación real para comprobar las transformaciones que puede sufrir la red por un evento concreto acaecido y mediante

ISSN: 0212-8594 ISSN-e: 2340-2776 № DOI: http://dx.doi.org/10.12795/rea.2012.i29.03

REA 29 (2012): 59-82

http://www.publius.us.es/estudios_andaluces 
el cual se pretende exponer cómo se puede analizar la vulnerabilidad en toda la red en una situación verdadera.

Tabla 1. Tiempos de desplazamientos internos

\begin{tabular}{|c|c|}
\hline Tamaño de los municipios & Tiempo interno (tiempo de salida + tiempo de llegada) \\
\hline Mayor de 50.000 habitantes & 11 minutos ( 5,5 de salida y 5,5 de llegada) \\
\hline Entre 25.000 y 50.000 habs. & 9 minutos ( 4,5 de salida y 4,5 de llegada) \\
\hline Entre 10.000 y 25.000 habs. & 7 minutos ( 3,5 de salida y 3,5 de llegada) \\
\hline Menor de 10.000 habitantes & 5 minutos ( 2,5 de salida y 2,5 de llegada) \\
\hline
\end{tabular}

Fuente: Elaboración propia.

Figura 1. Mapa de los municipios y de la red de carreteras de la isla de Mallorca.

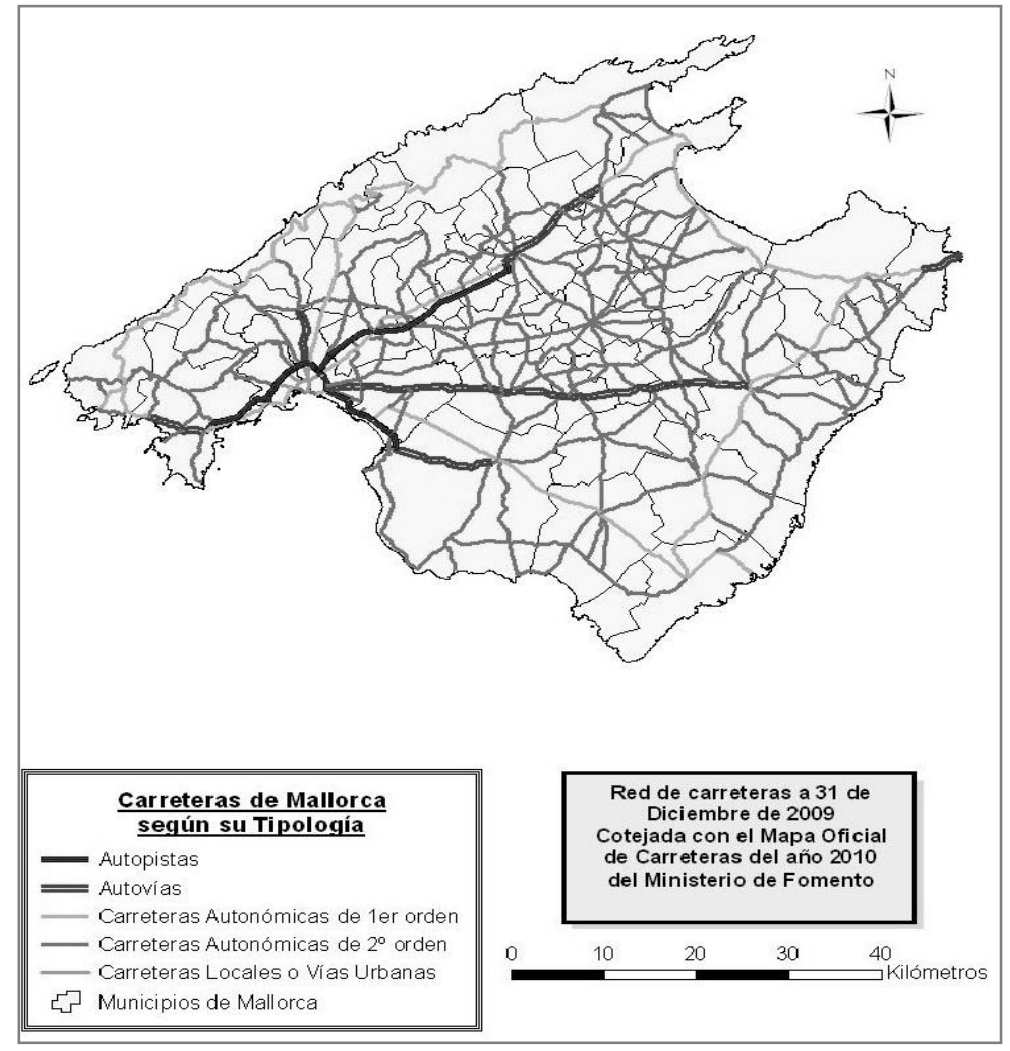

Fuente: Elaboración propia.

Los siete escenarios ficticios considerados se han considerado teniendo en cuenta que los tramos cortados que son el paso inmediato a zonas de Mallorca con una importancia destacada por su interés turístico o estratégico a nivel socioeconómico, por ser la vía de entrada o salida del aeropuerto, ser el único camino a puntos periféricos de la isla o simplemente por acceder a espacios con elevada población y tener una elevada intensidad media diaria de tráfico. En el contexto de la situación real la modificación de la accesibilidad se estima mediante los cambios dados en ocho tramos de la red tras las importantes lluvias del 3 de Mayo de 2010.

ISSN: 0212-8594 ISSN-e: 2340-2776 № DOI: http://dx.doi.org/10.12795/rea.2012.i29.03 
Esta accesibilidad potencial se estima con la siguiente fórmula:

$A_{p}=\sum \frac{P_{y}}{t_{x y} d}$

Siendo:

Apla accesibilidad potencial,

$t$ el tiempo de viaje en minutos entre un origen $x$ y un destino $y$,

del exponente de la distancia

$P_{y}$ la población de los destinos.

El exponente de la distancia se emplea como elemento que considera la fricción del espacio para la circulación de los flujos económicos, estimando monetariamente los desplazamientos y su puesta en valor en los mercados en el territorio con los datos de comercio entre las provincias españolas a fecha de 2005 (Condeço, A.M. et al., 2010).

La accesibilidad potencial de referencia (en condiciones de normalidad de la red, Figura 2) se ha obtenido para cada centroide municipal y luego se ha procedido, para una mejor interpretación en el conjunto de la isla, a una interpolación de los mismos. De igual modo se ha hecho en las situaciones de interrupción de los tramos analizados, obteniendo en estos escenarios tanto una serie de tablas de valores de accesibilidad como su representación a nivel cartográfico. Con la diferencia en porcentaje de los valores de accesibilidad entre la situación de referencia y las de los cortes se han elaborado una serie de mapas que muestran la variación porcentual de esos valores y a partir de ellos se han estimado los tramos más vulnerables de la red.

Finalmente, mediante una serie de sencillos cálculos estadísticos, tanto de tendencia central, con una media de la accesibilidad ponderada por la población de los municipios (Figura 3), como de dispersión, con el coeficiente de variación del cambio porcentual de la accesibilidad de los distintos escenarios considerados (Figura 4) respecto a una situación de normalidad de la red, se revelaría la agrupación, difusión y disparidades en los resultados, indicando cuáles serían los términos que alcanzan los niveles máximos y mínimos.

\subsection{ANÁLISIS DE UNA RED DE TRANSPORTE PÚBLICO - METRO DE MADRID.}

En una primera fase del análisis de la vulnerabilidad de la red de metro de Madrid se ha partido de la cifra de viajeros aforados en cada andén de cada estación durante todos los días del mes de Octubre de 2010, dato aportado por el Consorcio Regional de Transportes de Madrid. La tabla con los datos de las estaciones muestra el nombre de

ISSN: 0212-8594 ISSN-e: 2340-2776 № DOI: http://dx.doi.org/10.12795/rea.2012.i29.03

REA 29 (2012): 59-82

http://www.publius.us.es/estudios_andaluces 
Figura 2. Accesibilidad potencial en condiciones de normal funcionamiento de la red.

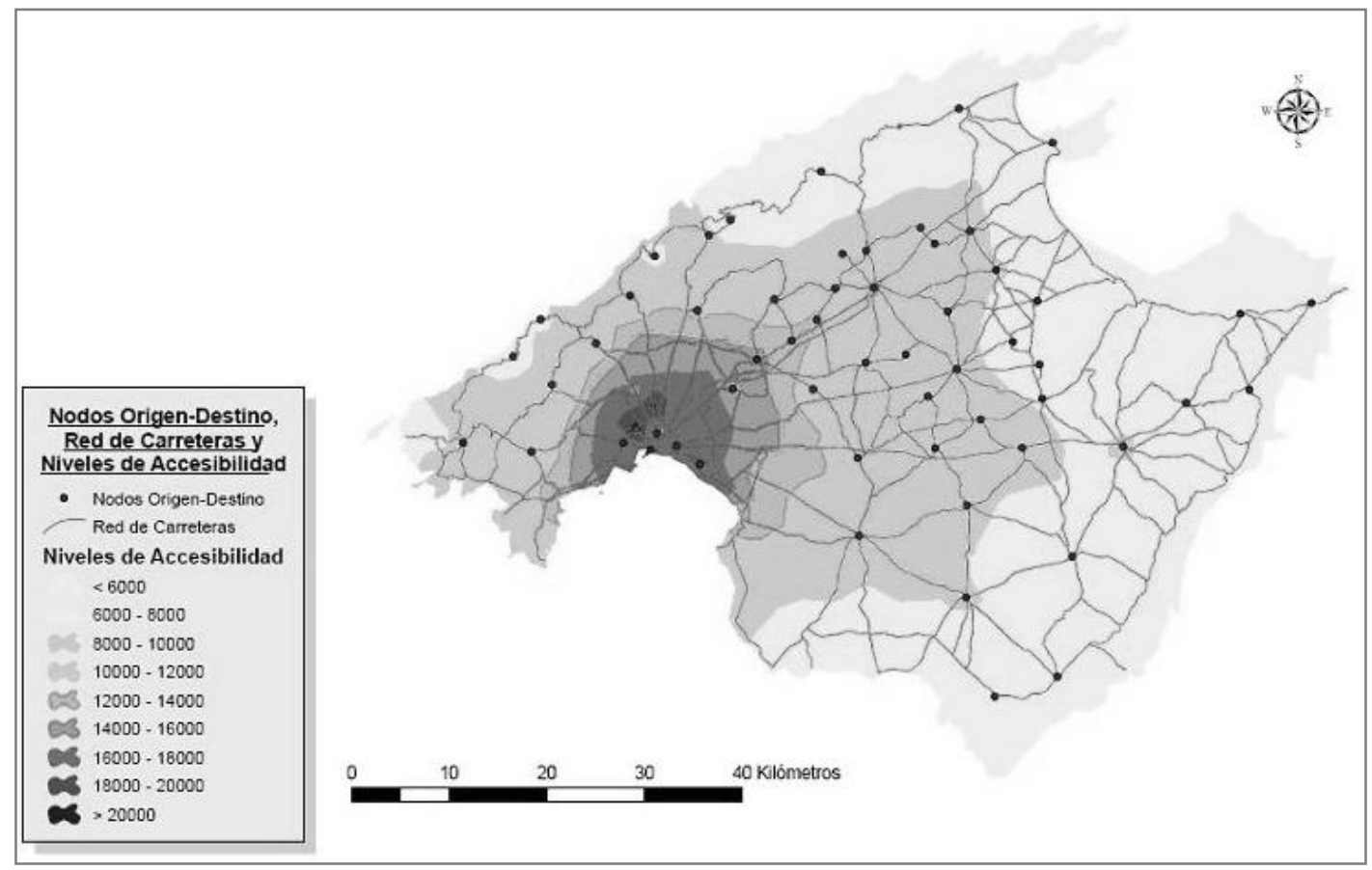

Fuente: Elaboración propia.

Figura 3. Media de la accesibilidad de la red de carreteras de Mallorca ponderada por la población.

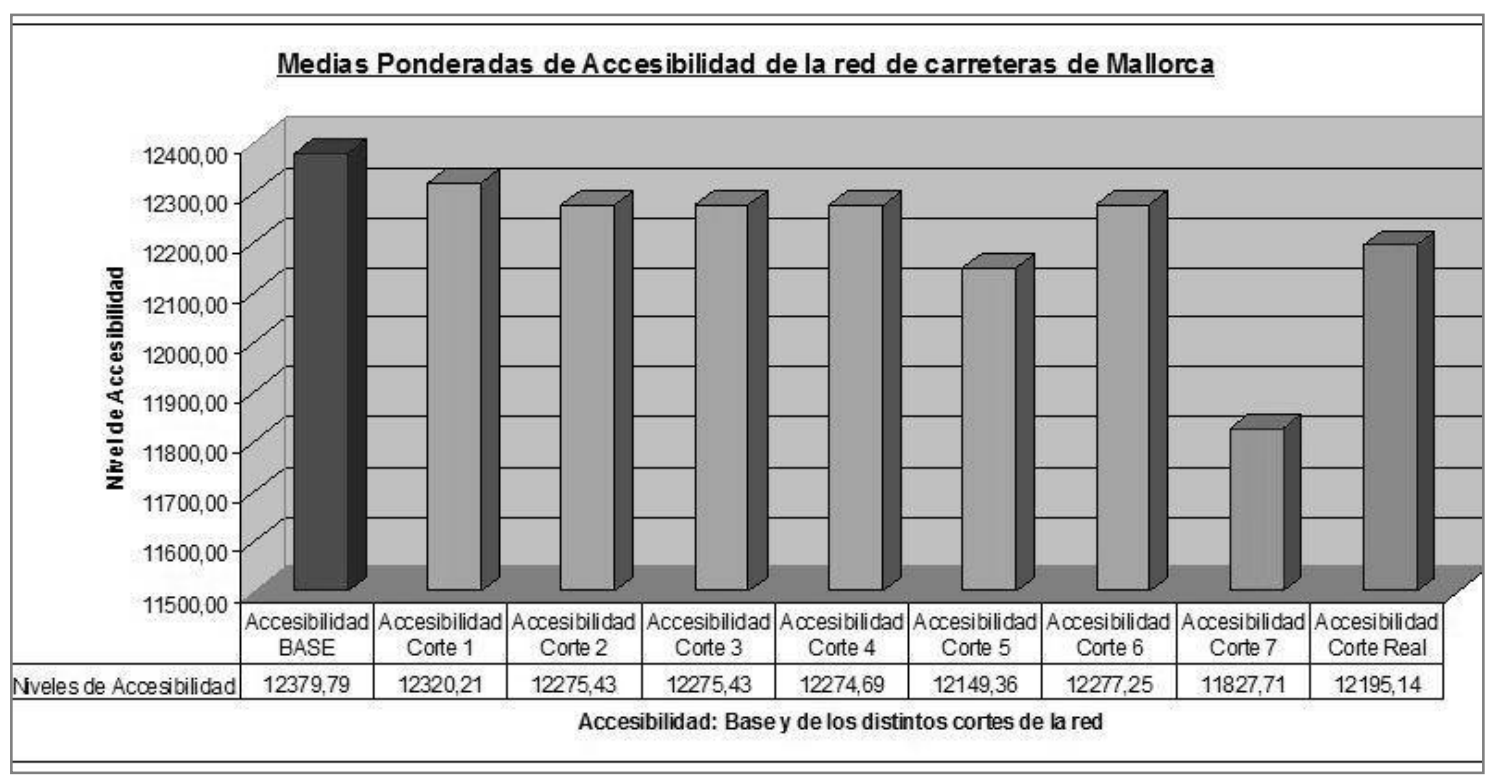

Fuente: Elaboración propia.

ISSN: 0212-8594 ISSN-e: 2340-2776 № DOI: http://dx.doi.org/10.12795/rea.2012.i29.03

REA 29 (2012): 59-82

http://www.publius.us.es/estudios_andaluces 
Figura 4. Coeficiente de variación (en \%) del cambio porcentual de la accesibilidad en cada uno de los escenarios contemplados

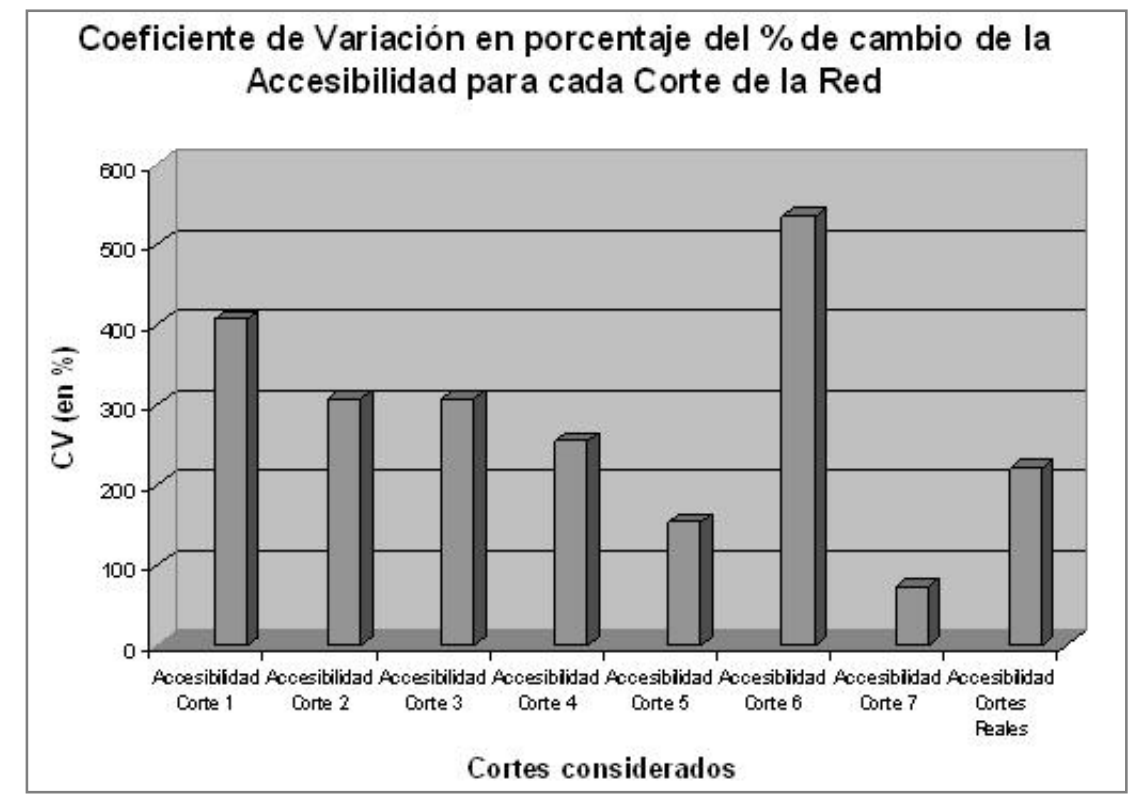

Fuente: Elaboración propia.

cada estación y la línea o líneas que pasan por ella, a la vez que considera si tienen dos o más andenes de las respectivas líneas que pasan por ellas y en las que se pueden realizan transbordos. La tabla de los tramos de las líneas que tiene la red contiene el tiempo de recorrido en minutos de cada uno de ellos, el cual servirá como valor de impedancia o fricción del movimiento, así como su longitud. Se incluyen tanto los arcos de los túneles como los de los pasillos que permiten los transbordos en estaciones con más de una línea.

Por otra parte, para su representación mediante un sistema de información geográfica (SIG) se tiene digitalizada toda la red de metro, actualizada a mediados de 2011, pero de la cual se han eliminado los tramos y estaciones inaugurados ese año y que no se hallaban operativos para la fecha de la que se disponen los datos -Octubre de 2010-, pues si no sería un estudio sin coherencia alguna (Figura 5).

Se ha procedido con los datos de viajeros a hacer una matriz origen-destino de todas a todas las estaciones analizadas (cifradas en 292), pero al no tener sentido calcular los tiempos de desplazamiento interno, pues no hay viajes de una estación hacia sí misma, como sucede en los municipios de Mallorca, se han eliminado este tipo de trayectos, lo que da un total de 84.972 relaciones posibles. 
Figura 5. Red de Metro de Madrid en el año 2010.

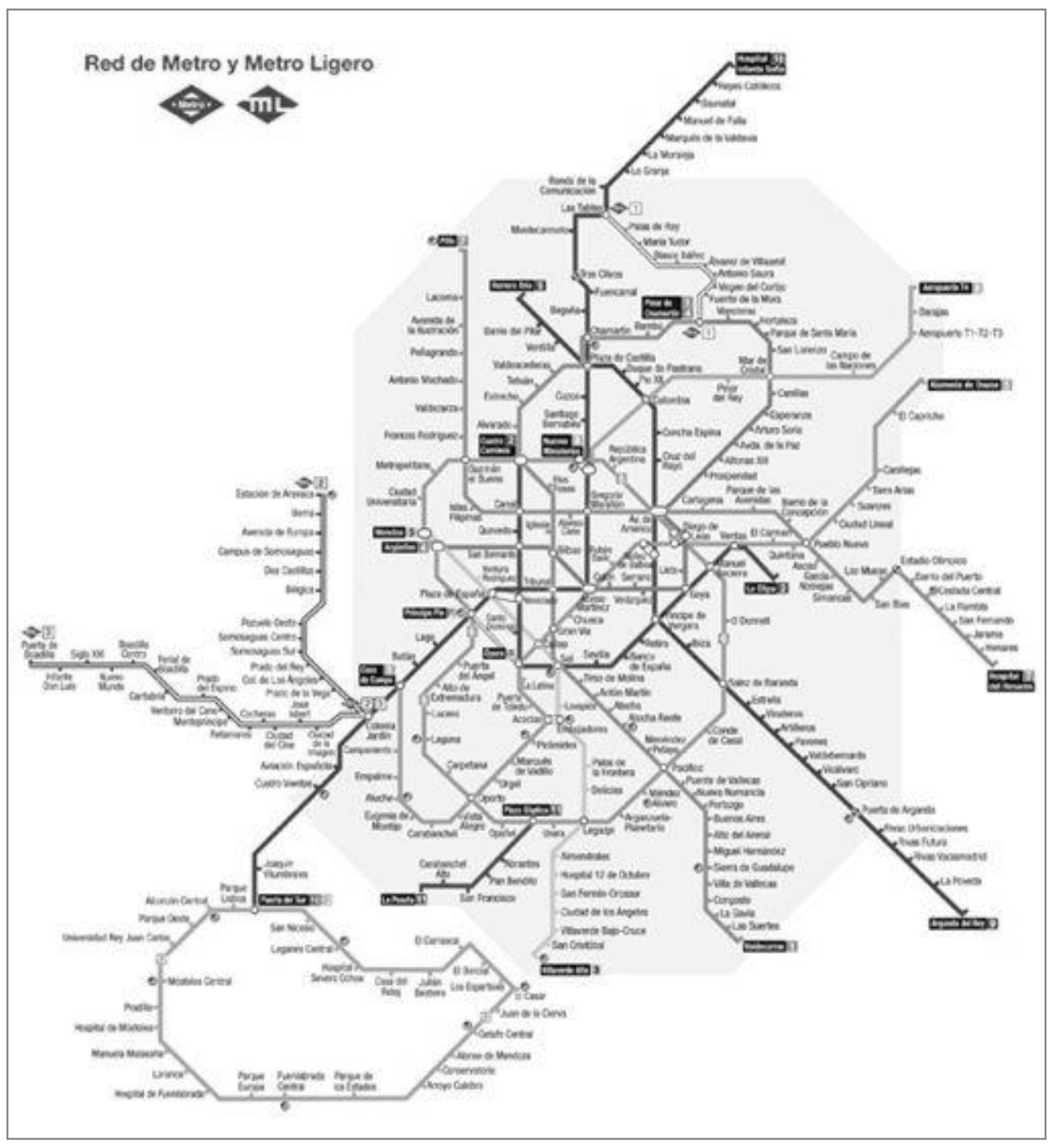

Fuente: Metro de Madrid.

Se ha procedido con los datos de viajeros a hacer una matriz origen-destino de todas a todas las estaciones analizadas (cifradas en 292), pero al no tener sentido calcular los tiempos de desplazamiento interno, pues no hay viajes de una estación hacia sí misma, como sucede en los municipios de Mallorca, se han eliminado este tipo de trayectos, lo que da un total de 84.972 relaciones posibles.

ISSN: 0212-8594 ISSN-e: 2340-2776 № DOI: http://dx.doi.org/10.12795/rea.2012.i29.03

REA 29 (2012): 59-82

http://www.publius.us.es/estudios_andaluces 
A partir de estas cifras se han obtenido una serie de medias iniciales, a saber, la media de viajeros para los días laborables de dicho mes, la media para los fines de semana y festivos y la media de viajeros para todo Octubre de 2010. Con estos valores medios se han obtenido, mediante la fórmula de la accesibilidad del apartado anterior, unas estimaciones de la accesibilidad potencial en una situación de normal funcionamiento de la red (Figura 6 y Figura 7), aunque no se ha utilizado un exponente $d$ y la población de los destinos es en este caso el número de viajeros que sale de cada estación, teniendo en cuenta que en estaciones con más de un andén cada uno de éstos tiene su propio valor de accesibilidad en función del número de viajeros que representen. Los datos proporcionados incluyen cifras de la Línea de Metro Ligero 1 (ML-1), pero no de las otras dos líneas de este tipo de transporte (la ML-2 y la ML-3).

Figura 6. Valores de la accesibilidad potencial para todas las estaciones de la red con los datos de la media de viajeros en días laborables de Octubre de 2010.

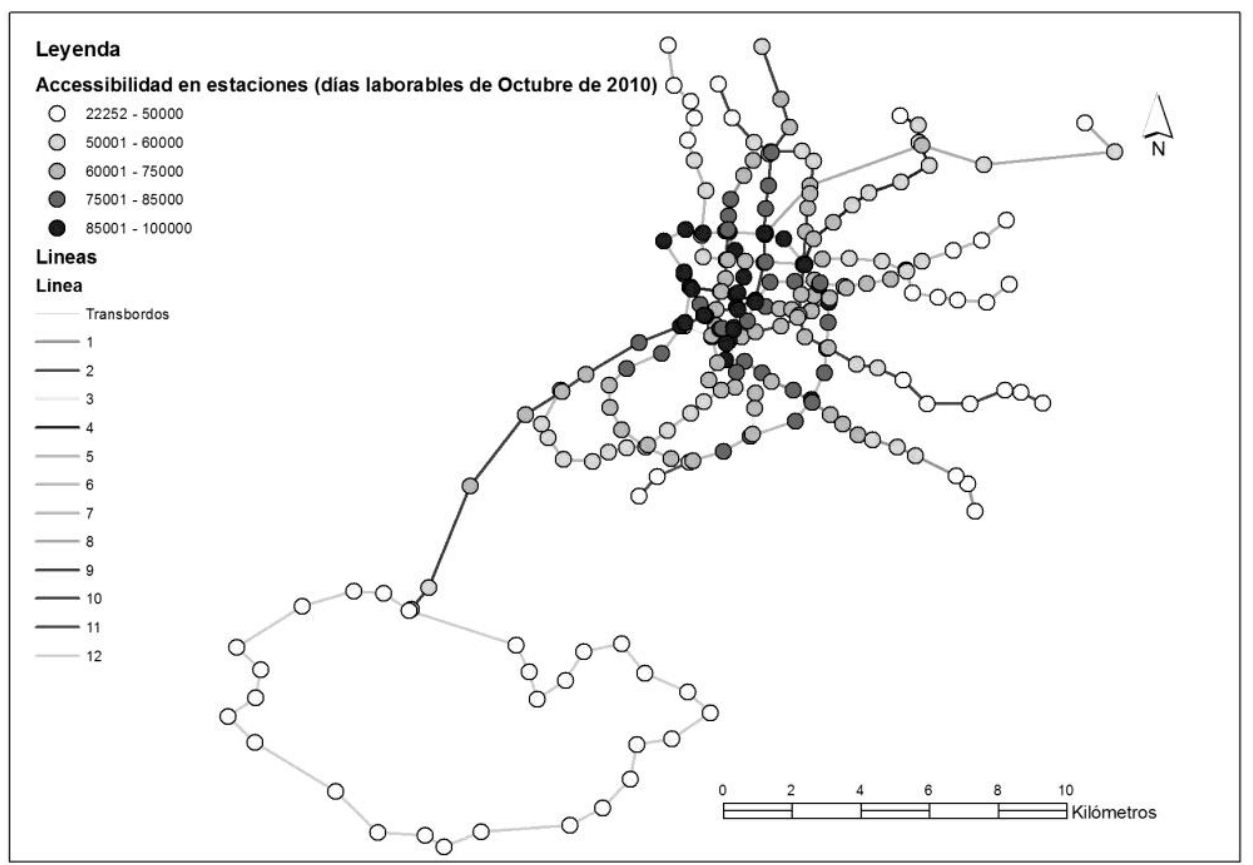

Fuente: Elaboración propia.

ISSN: 0212-8594 ISSN-e: 2340-2776 № DOI: http://dx.doi.org/10.12795/rea.2012.i29.03

REA 29 (2012): 59-82

http://www.publius.us.es/estudios_andaluces 
Figura 7. Valores de la accesibilidad potencial para todas las estaciones de la red con los datos de la media de viajeros de todo el mes de Octubre de 2010

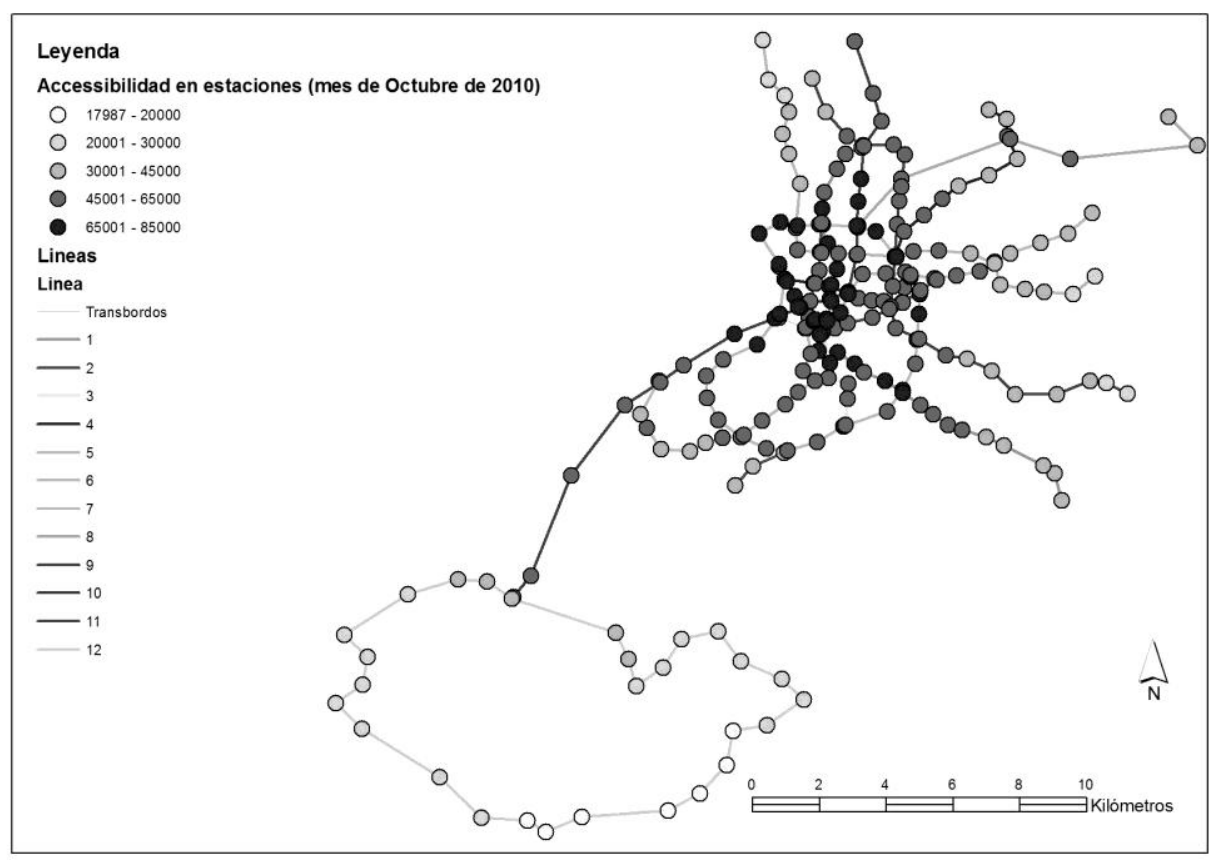

Fuente: Elaboración propia.

Figura 8. Valores de la accesibilidad para todas las estaciones de la red tras el corte del túnel entre las estaciones de Antón Martín y Atocha (Línea 1).

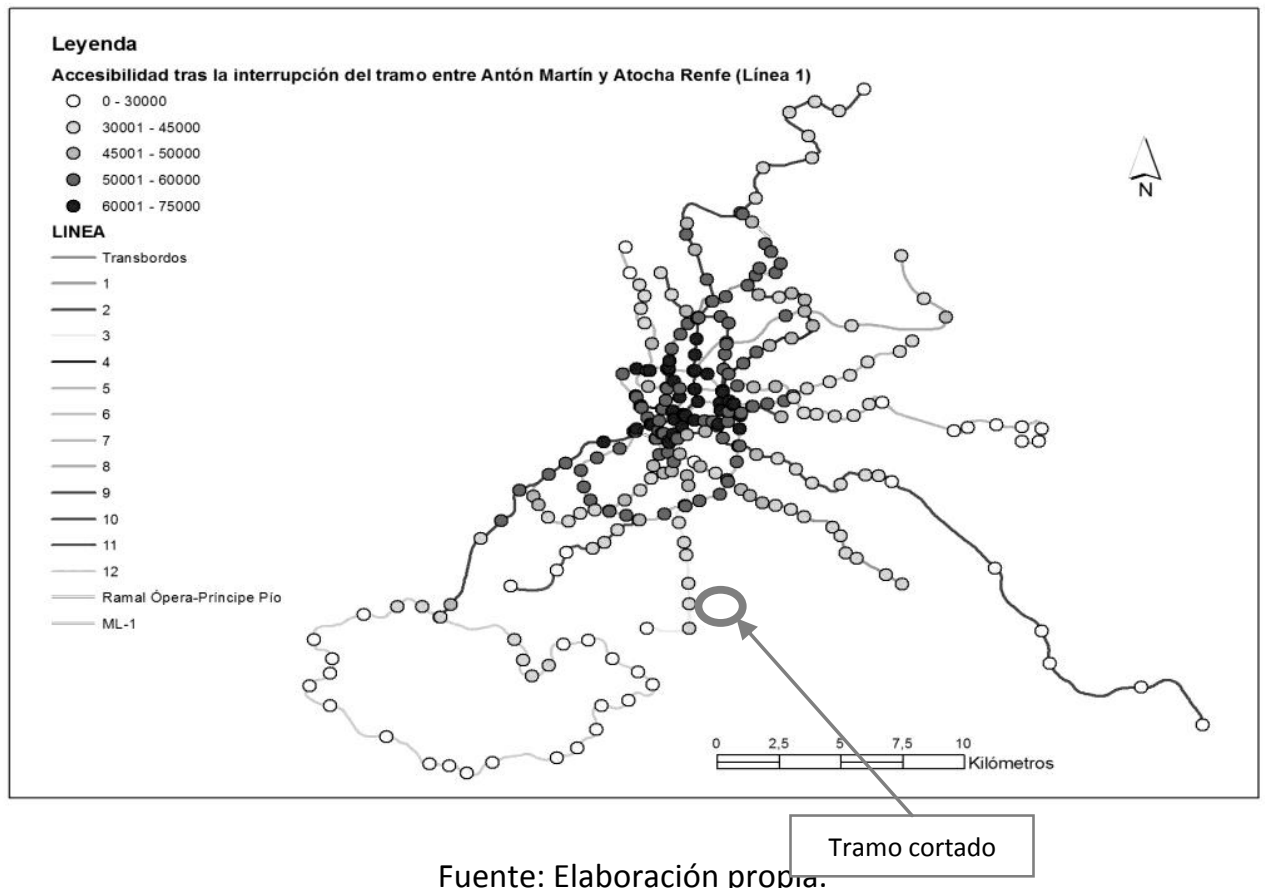

ISSN: 0212-8594 ISSN-e: 2340-2776 № DOI: http://dx.doi.org/10.12795/rea.2012.i29.03

REA 29 (2012): 59-82

http://www.publius.us.es/estudios_andaluces 
El hecho de obtener la accesibilidad potencial en las dos situaciones de los días laborables y en la media del mes tiene la finalidad de poder hacer una comparación de ambos periodos de tiempo para comprobar cómo afecta la influencia de los viajes por motivos de trabajo y estudio en los días laborables y cómo se diluye dicho influjo si los datos se consideran para todo el mes, con la aportación de los fines de semana y festivo. Asimismo, se pretende conocer cuáles serían las estaciones con mayor importancia en los días laborables en cuanto a niveles de accesibilidad en condiciones de normal funcionamiento de la red, que evidenciarían su importancia por ser puntos de elevada demanda y en las que se tendría que poner un especial énfasis para evitar interrupciones de la red en las mismas y en los tramos que confluyen hacia ellas.

De este modo, la vulnerabilidad de la red se estima también con los cambios en los valores de la accesibilidad de referencia de todas y cada una de las estaciones, frente a las cifras de dicha variable obtenidas en sucesos con uno o más cortes en la red.

En cuanto a los escenarios de interrupción de los tramos de la red, se ha considerado únicamente la paralización de los túneles que unen las estaciones pero no de los que hay dentro de una estación con más de un andén y que son utilizados por los viajeros para realizar los transbordos, partiendo de los datos de Octubre de 2010. Ante la dificultad de elegir algún tramo concreto, se han tomado aleatoriamente tres escenarios de corte de túneles, cada uno en una línea distinta:

- $\quad$ Entre las estaciones de Antón Martín y Atocha en la Línea 1 (Figura 8)

- Entre las estaciones de Ventas y Diego de León en la Línea 2 (Figura 9)

- Entre las estaciones de Guzmán el Bueno y Metropolitano en la Línea 6 (Figura 10)

\subsection{RESULTADOS.}

En este análisis de las carreteras de Mallorca, los valores de la accesibilidad (Figura 11) se encuentran polarizados por un lado en las áreas en que llega a sus niveles máximos son principalmente, Palma de Mallorca, y su zona de influencia inmediata, consecuencia directa de ser las zonas mejor comunicadas y con mayor número de habitantes, tanto en números absolutos como en densidad, y por otro en casi todo el borde costero, en los términos más apartados de estas poblaciones de los alrededores de la capital, en donde las cifras son significativamente más reducidas, lo cual acredita que las zonas con menor densidad de tramos son las que presentan índices más bajos de accesibilidad y por ello tienden a mostrar valores más elevados de vulnerabilidad.

De estos primeros resultados a grandes rasgos se deriva que los máximos valores en de la accesibilidad en cifras absolutas tenga su representación más significativa en los cinco distritos en los que se divide la capital, Palma, y en los términos aledaños a los mismos (como sucede en Consell, Marratxí y Santa María del Camí), lo que se traduce en que éstos tengan una concentración extrema en las diferentes observaciones

ISSN: 0212-8594 ISSN-e: 2340-2776 № DOI: http://dx.doi.org/10.12795/rea.2012.i29.03

REA 29 (2012): 59-82

http://www.publius.us.es/estudios_andaluces 
Figura 9. Valores de la accesibilidad para todas las estaciones de la red tras el corte del túnel entre las estaciones de Ventas y Diego de León (Línea 2).

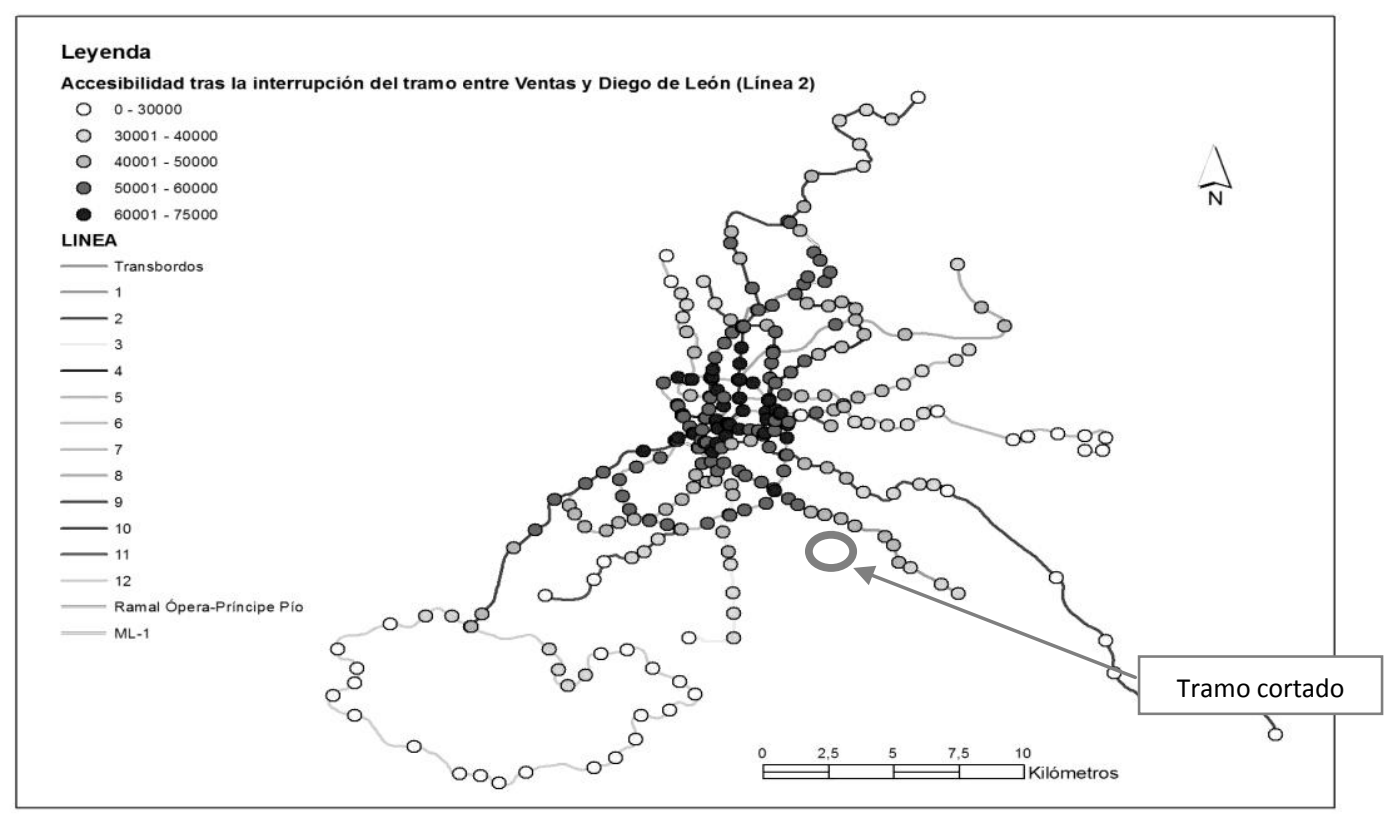

Fuente: Elaboración propia.

Figura 10. Valores de la accesibilidad para todas las estaciones de la red tras el corte del túnel entre las estaciones de Guzmán el Bueno y Metropolitano (Línea 6).

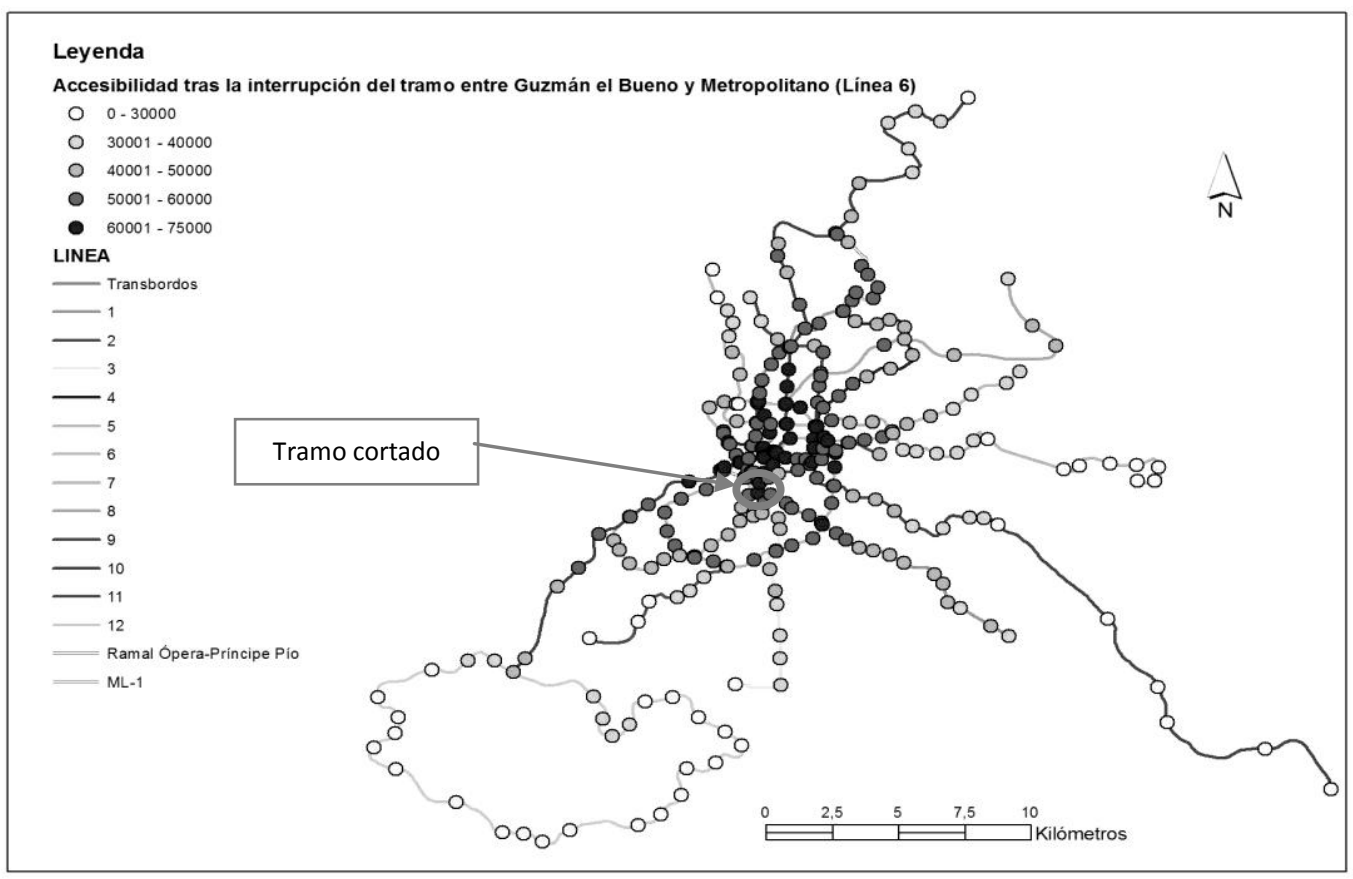

Fuente: Elaboración propia.

ISSN: 0212-8594 ISSN-e: 2340-2776 № DOI: http://dx.doi.org/10.12795/rea.2012.i29.03

REA 29 (2012): 59-82

http://www.publius.us.es/estudios_andaluces 
realizadas. Todo ello viene refrendado por los resultados de los cálculos estadísticos, tanto de las medias como de los coeficientes de variación.

Por otro lado, en este análisis de la red de carreteras de Mallorca se ha comprobado que algún tramo de la red sirve de vía alternativa para que siga cumpliendo con su servicio cuando se da alguna alteración, aún a costa de un mayor tiempo de desplazamiento, como sucede en la carretera paralela a la autovía que va de Palma a Inca y Alcudia. Pero prácticamente en el resto de la red no hay otros trayectos redundantes que pudieran descongestionar y aportar una solución en situaciones de eventos conflictivos.

En la evaluación de la vulnerabilidad de la red de metro de Madrid la situación se encuentra también fuertemente polarizada entre las estaciones del centro y las de la periferia. Como ejemplo, en los días laborables ostentan los mayores índices de accesibilidad las estaciones más céntricas de la línea 10 (Gregorio Marañón, Alonso Martínez y Tribunal) y de la línea 1 (Gran Vía y Tribunal, seguidas de Sol y Tirso de Molina), por ser áreas de gran atracción por la cantidad de oficinas y comercios que hay en sus alrededores. A nivel mensual, en donde entra el peso de la demanda durante los fines de semana y festivos, con más desplazamientos motivados por razones de ocio, las estaciones con los indicadores más elevados de accesibilidad son también esas estaciones localizadas en la parte central de las líneas 1 (Gran Vía y Tribunal) y 10 (Tribunal, Alonso Martínez y Gregorio Marañón) (Figura 12). En ambos casos las estaciones con las cifras más bajas se encuentran tanto en la línea 12 conocida también como MetroSur, de forma circular y que une los cinco municipios más poblados al Suroeste de la capital- como son Parque de los Estados - en Fuenlabrada, Arroyo Culebro y Conservatorio - en Getafe (Figura 13), como en la línea 7, al Este de la capital y ya en el término de Coslada, en las estaciones de Jarama, Henares y Hospital del Henares.

Los resultados de la accesibilidad resultante en los tres casos de interrupciones tomadas al azar muestran como en los andenes de las estaciones implicadas en la interrupción de los tramos (Antón Martín, Atocha, Ventas, Diego de León, Guzmán el Bueno y Metropolitano) la accesibilidad es sumamente baja, o incluso nula, mientras que en ciertas estaciones céntricas de la red (Alonso Martínez, Tribunal y Gregorio Marañón en la línea 10; República Argentina y Diego de León en la línea 6 -en esta última excepto en el caso del corte en la línea 2 de su otro andén, que tiene cierto efecto en el andén de la línea 6; las estaciones centrales de la línea 1 no ostentan ya los máximos valores, si bien son aún altos) se mantienen valores elevados que las distinguen del resto. Además de en las andenes afectados directamente por los cortes, la accesibilidad obtenida vuelve a ser mínima nuevamente en las estaciones del extremo oriental de la línea 7 (Henares, Hospital del Henares, Jarama), del final suroriental de la línea 9 (Arganda del Rey) y en alguna estación más alejada de la línea 12 (Arroyo Culebro).

ISSN: 0212-8594 ISSN-e: 2340-2776 № DOI: http://dx.doi.org/10.12795/rea.2012.i29.03

REA 29 (2012): 59-82

http://www.publius.us.es/estudios_andaluces 


\section{Eduardo Rodríguez Núñez}

Estudio de la vulnerabilidad de las redes de transporte desde una perspectiva geográfica.

Figura 11. Municipios de Mallorca con mayores y menores niveles de accesibilidad.

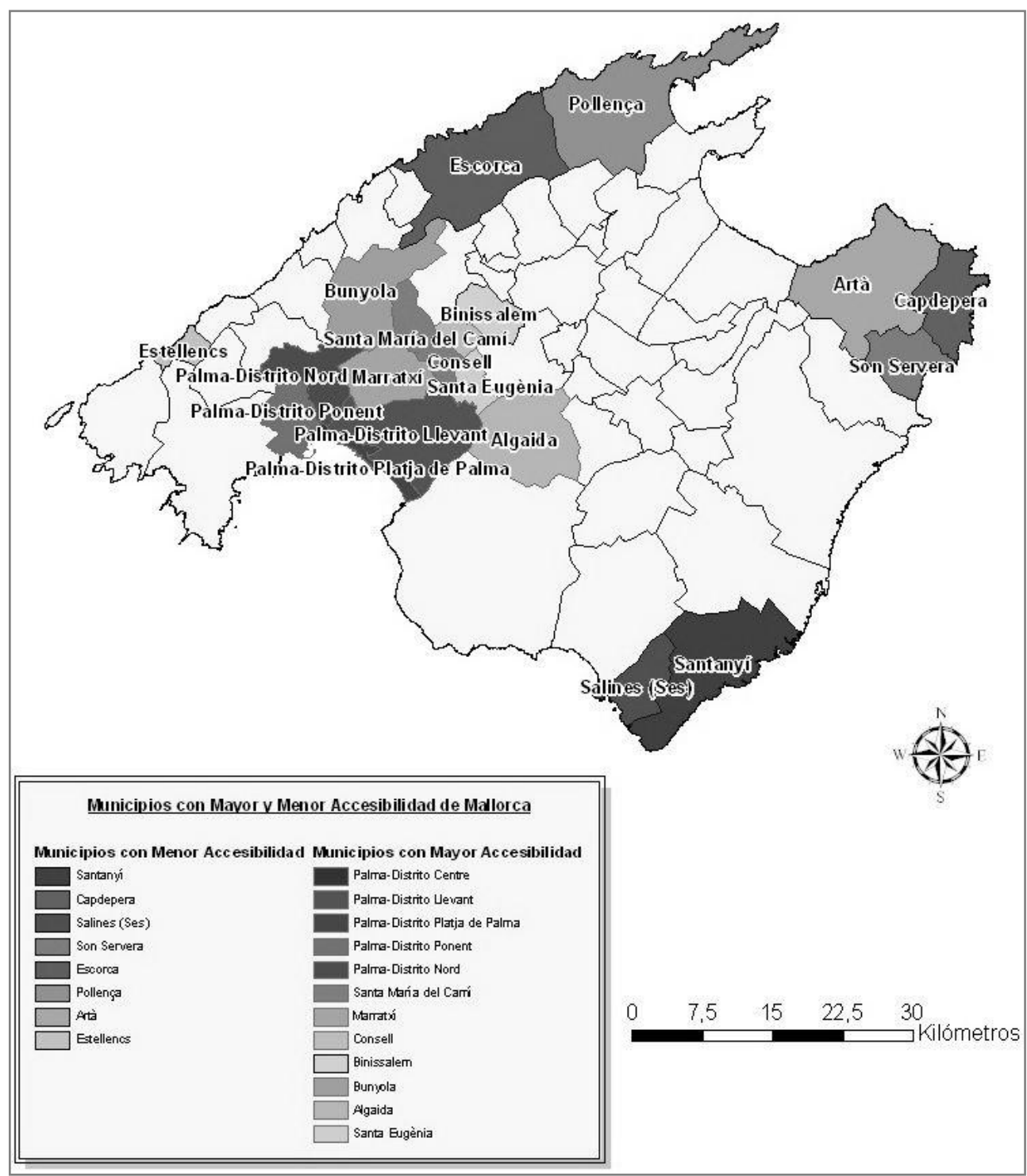

Fuente: Elaboración propia.

ISSN: 0212-8594 ISSN-e: 2340-2776 № DOI: http://dx.doi.org/10.12795/rea.2012.i29.03

REA 29 (2012): 59-82

http://www.publius.us.es/estudios_andaluces 
Figura 12. Estaciones con mayores niveles de accesibilidad, tanto en la situación de partida como en los distintos escenarios de corte considerados

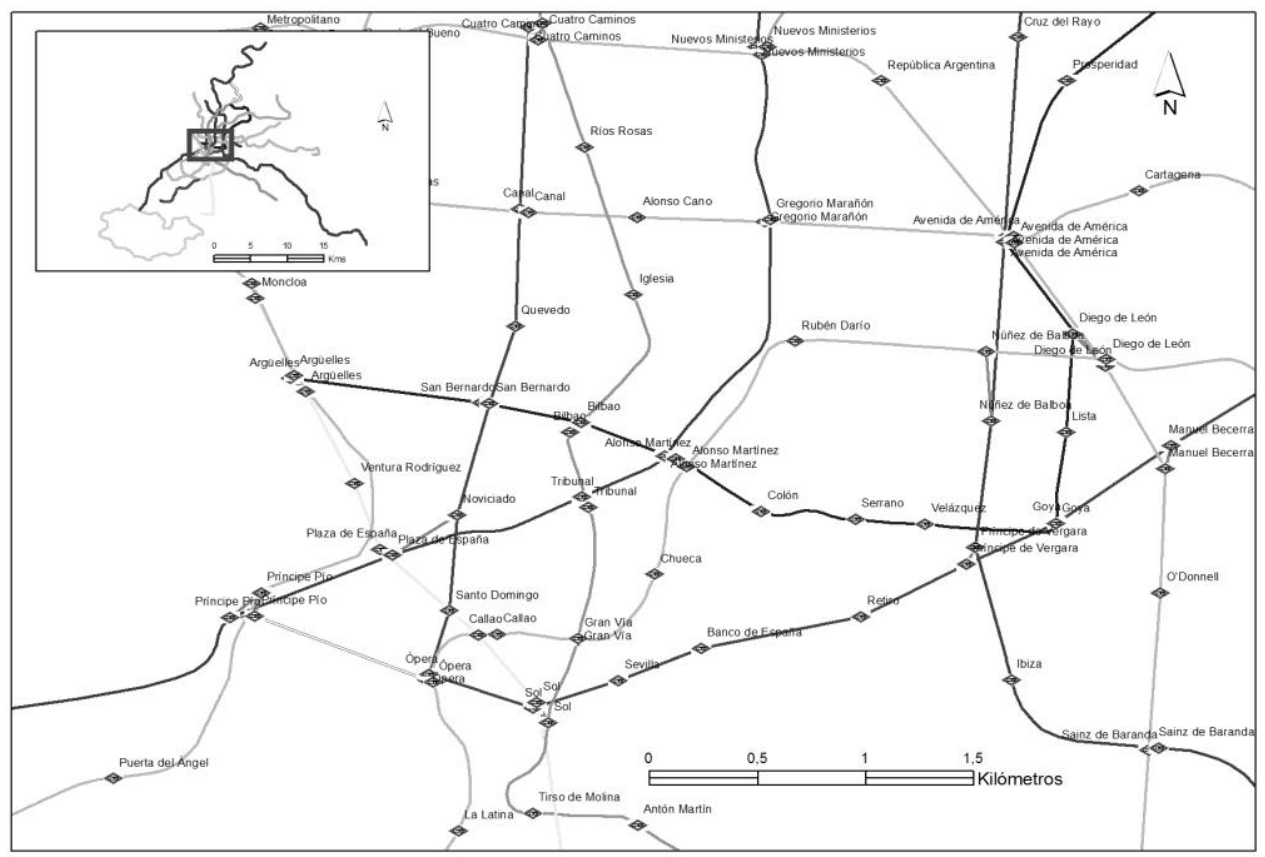

Fuente: Elaboración propia.

Figura 13. Estaciones de la línea 13 (MetroSur) con los valores más bajos de accesibilidad, tanto en la situación de partida como en los distintos escenarios de corte.

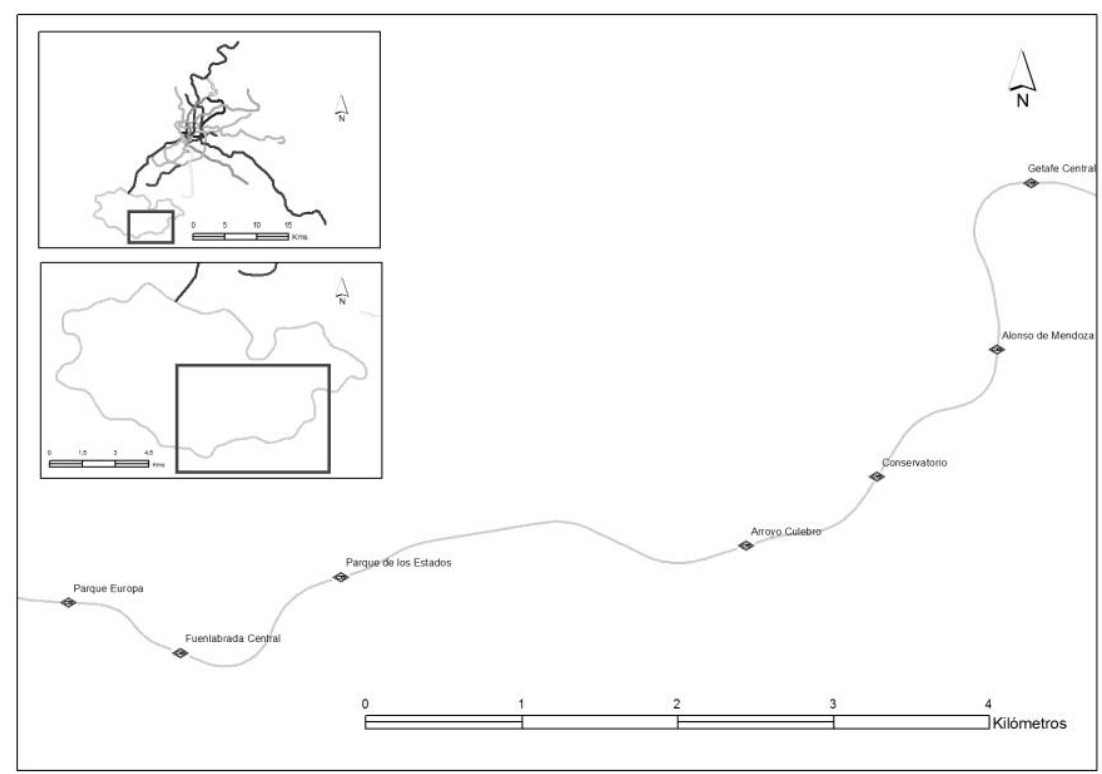

Fuente: Elaboración propia.

ISSN: 0212-8594 ISSN-e: 2340-2776 № DOI: http://dx.doi.org/10.12795/rea.2012.i29.03 REA 29 (2012): 59-82

http://www.publius.us.es/estudios_andaluces 
En una segunda fase del estudio de esta red de metro y como un progreso en el desarrollo de la investigación (a la espera de la obtención de los datos de viajeros relativos al número medio de viajeros entre cada par de estaciones para el año 2007), se pretende obtener los flujos que indiquen la relevancia de todos y cada uno de los tramos de la red, partiendo del números de viajeros que soportan en el conjunto de los desplazamientos, a fin de establecer cuáles de ellos pueden resultar más vulnerables.

\section{CONCLUSIONES.}

En el caso de la red de carreteras de Mallorca, se puede establecer que los municipios con más habitantes, que a su vez suelen contar con vías de alta capacidad, esto es, más densidad de tramos, de mejor calidad y mayor acogida de aforo de tráfico, como autovías y autopistas, son los que muestran una mayor accesibilidad y por tanto una clara indicación de que la vulnerabilidad de los mismos es así menor. Por el contrario, en zonas donde la densidad viaria es mucho más reducida, especialmente en la costa, y en donde los valores de la accesibilidad son notoriamente bajos, se aprecia que el grado de vulnerabilidad es elevado.

De ambas situaciones se extrae que, partiendo del punto de vista de la accesibilidad, en la red de carreteras analizada la vulnerabilidad presenta índices exiguos mientras se mantenga un doble vínculo de numerosa población y entramado compacto de carreteras, lo que claramente favorece a las áreas más urbanizadas, mientras que la situación contraria se dará en espacios con una abierta malla de tramos de la red. Por lo tanto, se debería mejorar la red en estos lugares donde muestra baja densidad, por lo menos en cuanto a su fiabilidad y nivel de servicio, para que las situaciones en que haya un destacado riesgo de representar una alteración sean las mínimas posibles.

Respecto a la red de metro de Madrid, la mayor demanda de viajeros establecida en una serie de estaciones centrales de la red, por motivos de acceder a los centros de trabajo o de consumo de bienes y servicios, se traduce en unos valores de accesibilidad más cuantiosos en las mismas y muestra la importancia que tienen en el conjunto de la red. El hecho de que en los tramos que las comunican se produzca una interrupción del servicio provocaría unas consecuencias de cierta gravedad y las sitúa como los ámbitos de la red que mayor vulnerabilidad representan. Como contrapartida, las estaciones más periféricas, en una red notablemente radial como esta, son las que mantienen una accesibilidad menor y que, por relación directa de la topología que las configura como fondo de saco, de la cantidad de usuarios que se apean en ellas y de la elevada distancia en tiempo que las separan de las del resto de la red, las hacen también vulnerables, pero cuyos efectos en caso de una alteración del funcionamiento serían mucho menores que en el caso de los andenes más céntricos.

Por tanto, el énfasis en la red, si bien sería mantenerla toda en unas condiciones de servicio adecuadas, se centraría en las estaciones que acogen un mayor flujo de

ISSN: 0212-8594 ISSN-e: 2340-2776 № DOI: http://dx.doi.org/10.12795/rea.2012.i29.03

REA 29 (2012): 59-82

http://www.publius.us.es/estudios_andaluces 
viajeros, que a la vez permiten realizar transbordos entre líneas y reducir el tiempo de los viajes a la parte central de la ciudad, ante la demanda que en ésta se produce.

\section{ANÁLISIS FUTUROS.}

Dentro de los planteamientos para desarrollar nuevos estudios sobre la vulnerabilidad de redes de transporte se considera la posibilidad de colaborar con entidades públicas de gestión del tráfico y/o del transporte. Con esa perspectiva, se ha contactado con la Dirección General de Tráfico (DGT) y con la empresa Metro de Madrid, que permitan en un futuro inmediato avances sustanciales en las investigaciones de las redes de su competencia, mediante la aportación de nuevos datos actualizados y de su experiencia como gestores de estos medios de transporte.

Al tener las carreteras un interés especial para el desplazamiento de la población, se considera estudiarla vulnerabilidad de los "puntos negros" o zonas de concentración de accidentes (ZCA) de la red de carreteras de interés general del Estado (RIGE), a partir de información proporcionada por la DGT, debido a los posibles daños y repercusiones al tránsito de viajeros y mercancías. En otra escala, este tipo de análisis se podría enfocar hacia las carreteras locales -en muchos casos con importancia regional- en el entorno de las grandes ciudades españolas, ante la cuantiosa demanda de usuarios en las mismas y en las que una alteración ocasiona notables efectos de demora en sus tiempos de desplazamiento, o sobre la red europea de carreteras, de gran repercusión, sobre todo por el transporte de mercancías y por los desplazamientos de ocio y turismo.

Las investigaciones sobre la vulnerabilidad se podrían dirigir también a otro tipo de redes: En los ferrocarriles de España, por un lado la red de alta velocidad, cuyos elevados costes de construcción y mantenimiento así como su creciente demanda exigen mantener una especial atención sobre ella, y por otro, las redes de cercanías, vitales para el acceso cotidiano de un nutrido contingente de población a sus lugares de trabajo, consumo, ocio y residencia; sobre las redes de transporte aéreo, en un país con tantos aeropuertos y donde las comunicaciones son esenciales en el caso de las islas y para el sostenimiento del sector turístico; y por último, en las redes marítimas, con el impulso de la Unión Europea al cabotaje y las autopistas del mar y su importancia para el tráfico de mercancías, motor de las importaciones y exportaciones.

\section{BIBLIOGRAFÍA}

Aymerich, O. y Robusté, F. (1990): “Fiabilidad de redes de transporte bajo condiciones excepcionales". Transportes y Telecomunicaciones, 42, pp. 25-37 
Berdica, K. (2002): “An introduction to road vulnerability: what has been done, is done and should be done". Transport Policy, 9, pp. 117-127 http://dx.doi.org/10.1016/S0967-070X(02)00011-2

Berdica, K. (2007): "Vulnerability: A Model-Based Case Study of the Road Network in Stockholm", en Murray, A. and Grubesic, T. (Eds.): Critical Infrastructure. Reliability and Vulnerability. Berlin, Springer, pp. 81-106

Chang, S. E. (2003): "Transportation planning for disasters: an accessibility approach". Environment and Planning A, vol. 35, pp. 1051-1072 http://dx.doi.org/10.1068/a35195

Chen,0 A.; Yang C., Lee M. and Kongsomsaksakul S. (2007): "Network-based Accessibility Measures for Vulnerability Analysis of Degradable Transportation Networks". Networks \& Spatial Economics, 7, pp. 241-256

Condeço, A.M.; Gutiérrez J. y García J. C. (2010): “Influencia de la fricción de la distancia en la medición del potencial de mercado y el efecto desbordamiento de las infraestructuras de transporte". En prensa, pp. 1-22

Cova t. J. (1999): "GIS in emergency management". Geographical Information Systems, Vol. 2. New York, John Wiley, pp. 845-858

Criado, R.; Flores, J.; Hernández-Bermejo, B.; Pello, J. and Romance, M. (2004): "Effective measurement of network vulnerability under random and intentional attacks".Journal of MathematicalModelling and Algorithms, 4, pp. 307-316 http://dx.doi.org/10.1007/s10852-005-9006-1

Criado, R.; Hernández-Bermejo, B. and Romance, M. (2006): “Efficiency, vulnerability and cost: An overview with applications to subway networks worldwide". International Journal of Bifurcation and Chaos, Vol. 17, No. 7, pp. 2289 - 2301 http://dx.doi.org/10.1142/S0218127407018397

Criado R.; Pello, J.; Romance, M. and Vela-Pérez, M. (2008): "A node-based multiscale vulnerability of complex networks". International Journal of Bifurcation and Chaos, Vol. 19, No. 2, pp. 703-710 http://dx.doi.org/10.1142/S0218127409023068

Díaz Pineda, J. (2000): "Introducción al problema de la Vulnerabilidad de las infraestructuras de carreteras". Carreteras, Revista técnica de la Asociación Española de la Carretera, Madrid, 106, pp. 7-29

Dragu, V., Stefanica, C. and Burciu, S. (2011): "Accessibility Study on Regard to Bucharest Underground Network". University Politechnica of Bucharest Science Bulletin, Series D, Vol. 73, Issue 1, pp. $221-236$

ISSN: 0212-8594 ISSN-e: 2340-2776 № DOI: http://dx.doi.org/10.12795/rea.2012.i29.03 
Erath, A.; Birdsall, J.; Axhausen, K.W. and Hajdin, R. (2008): "Vulnerability assessment of the Swiss road network". Research Report.EidgenössischeTechnischeHochschule, InstitutfürVerkehrsplanung und Transportsysteme (ETH-IVT), Zurich

Han, C. and Liu L,. (2009): "Topological vulnerability of subway Networks in China". Management and Service Science, 2009, pp. $1-4$

Hansen, W.G. (1959): "How Accesibility Shapes Land-Use".Journal of the American Institute of Planners, 5, pp. 76-106

Jenelius, E. and Mattsson, L.-G. (2006a): "Developing a methodology for road network vulnerability analysis". Nectar Cluster 1 Seminar, 12th - 13th May 2006, Molde University College, Molde (Norway)

Jenelius, E., Petersen, T. and Mattsson, L-G.(2006b): "Importance and exposure in road network vulnerability analysis".Transportation Research Part A 40, pp. 537-560 http://dx.doi.org/10.1016/j.tra.2005.11.003

Jenelius, E. (2007): "Incorporating Dynamics and Information in a Consequence Model for Road Network Vulnerability Analysis".Third International Symposium on Transportation Network Reliability (INSTR), The Hague, The Netherlands, July 19-20, 2007.

Jenelius, E. (2009a): "Considering the User Inequity of Road Network Vulnerability".Journal of Transport and Land Use, in press.

Jenelius, E. (2009b): "Network structure and travel patterns: Explaining the geographical disparities of road network vulnerability." Journal of Transport Geography 17(3), pp. 234-244 http://dx.doi.org/10.1016/j.jtrangeo.2008.06.002

Johnson, R. (1987): "Reliability and Survivability Issues in Network Design: A Survey", AT \& T Bell Laboratories, New Jersey.

Jung, W-S.; Lee K.; Park J. S. and Choi, M. Y. (2008): "Statistical analysis of the Metropolitan Seoul Subway System: Network structure and passenger flows". Physica A, 387, pp. $6231-6234$ http://dx.doi.org/10.1016/j.physa.2008.06.035

Kwan M-P.; Murray, A.T.; O'Kelly, M. E. and Tiefelsdorf, M. (2003): "Recent advances in accessibility research: Representation, methodology and applications". Journal of Geographical Systems, 5, pp.129-138 http://dx.doi.org/10.1007/s101090300107

Latora, V. and Marchiori, M. (2002): "Is the Boston subway a small-world network?" Physica A, 314, pp. 109 - 113 http://dx.doi.org/10.1016/S0378-4371(02)01089-0

Latora, V. and Marchiori, M. (2005): "Vulnerability and protection of infrastructure networks".Physical Review E, 71, pp. 015103-1-015103-4

ISSN: 0212-8594 ISSN-e: 2340-2776 № DOI: http://dx.doi.org/10.12795/rea.2012.i29.03 
Litman, T. (2011). "Evaluating Accesibility for Transportation Planning".Victoria, Victoria TransportPolicyInstitute. Consulta: 03-02-2011. Disponible en: http://www.vtpi.org/access.pdf

Nicholson, A. J. and Du, Z. P. (1994): "Improving Network Reliability: a framework". Proceedings of $17^{\text {th }}$ Australian Road Research Board Conference, 17 (6), pp.1-17.

Rey, C. E. y Cardozo, O. D. (2009):“La Vulnerabilidad en la movilidad urbana. Aportes teóricos y metodológicos", en Foschiatti, A. M. (coord./comp./autor): Aportes conceptuales y empíricos de la Vulnerabilidad global, EUDENE, Resistencia (Chaco), pp. 397-425

Ribas Palom, A. y Saurí Pujol, D. (2006): “De la Geografía de los Riesgos a las Geografías de la Vulnerabilidad", en: Nogué, J. y Romero, J. (coord.), Las Otras Geografías, Tirant Lo Blanch, Valencia, pp. 285-299

Sohn, J. (2006): "Evaluating the significance of highway network links under the flood damage: An accessibility approach".Transportation Research Part A, 40, pp. 491-506 http://dx.doi.org/10.1016/j.tra.2005.08.006

Taylor, M. A. P.; Sekhar, S. V. C. and D’Este G. M. (2006): “Application of Accessibility Based Methods for Vulnerability Analysis of Strategic Road Networks". Networks \& Spatial Economics, no 6. pp. 267-291 http://dx.doi.org/10.1007/s11067-006-9284-9 